\title{
Development of green insulation boards from kenaf fibres and polyurethane
}

\begin{abstract}
The purpose of this study was to develop effective green insulation boards fabricated from polyurethane (PU) reinforced with Kenaf fibres. Biocomposites having three different weight contents (40/60, 50/50 and 60/40 Kenaf/PU weight \%) were manufactured. A fourth type was made from 60/40 $\mathrm{NaOH}$-treated Kenaf/PU weight \%. The results show that the elastic properties increased with Kenaf fibre content. The optimal performance was observed at a weight of $50 \%$ Kenaf fibres. Furthermore, the minimum water absorption percentage, thickness swelling, and changing in volume were recorded at a weight of $50 \%$ kenaf fibres.
\end{abstract}

Keyword: Biocomposites; Natural materials; Polyurethane 